\title{
New Horizons for the Canadian Journal of Hospital Pharmacy
}

Stephen Shalansky

The Canadian Society of Hospital Pharmacists (CSHP) is undergoing numerous changes, due in part to the impact of the COVID-19 pandemic on its financial situation. The Canadian Journal of Hospital Pharmacy (CJHP) is among the CSHP initiatives that will be joining this journey toward a more sustainable future. The recent events that prompted this re-evaluation have also presented an opportunity to rethink our approach to publishing the $C J H P$, which has remained largely unchanged for many years. After reviewing the latest readership data, the Editorial Board has carefully considered both the Journal's strengths and its areas for potential improvement, and how we might capitalize on the changing publication landscape. The aim is to improve all aspects of the way we publish the Journal, a resource that we have all trusted and relied upon over the years.

First, we are making some technological upgrades. For the purpose of manuscript submissions, we will be transitioning away from the current eJournalPress platform to Open Journal Systems (OJS) 3 software. In addition, we will be upgrading to the OJS 3 software system for Journal publication. OJS 3 offers a streamlined, fresh display and functional user interface. It provides a more straightforward submission process and includes a responsive design that adjusts to readers' screen size on smartphones and tablets, as well as on desktop computers. It will also streamline overall workflow for Journal staff. You will notice as well that the CJHP layout has been redesigned to an easierto-read format.

CJHP will be reducing the number of issues published each year from six to four. This reduction in frequency will result in a slightly higher threshold for sending manuscripts out for review and for final acceptance. Another strategy for retaining quality while reducing the number of manuscripts published annually will be to omit some categories and update our Author Guidelines accordingly. As a result, the CJHP will no longer be publishing the following types of articles: stability studies, correspondence (including Research Letters), book reviews, and some types of editorials. We will also be ceasing the Advanced Pharmacist Practitioner series. At the same time, we will be introducing a new research category to accommodate shorter research reports (1500-word limit). The new category is being created in response to commonly encountered submissions that do not meet the requirements for a full-length Original Research manuscript, but include valuable information beyond the capacity of our traditional Research Letter criteria. We anticipate that many hospital pharmacy residency projects will be a good fit within this new category.

For the manuscript categories retained, we will be changing the word limits. For example, the abstract of Original Research articles will be limited to 250 words and the body of the article to 3000 words. The number and size of tables, figures, and references will also be re-evaluated and reduced where appropriate. We will also be implementing a 1500-word limit for the Innovations in Pharmacy Practice section and a 4000-word limit for Review articles. The Journal is also evaluating the possibility of a nominal submission fee (e.g., \$100) for manuscripts accepted for publication, to help improve authors' commitment to quality before submission. The CJHP's Author Guidelines have been updated to include full details of these changes and are now available at https://www.cjhp-online.ca/public/author _guidelines_english.pdf

Finally, the CJHP is taking this opportunity to revamp our reviewer database. The quality of manuscripts accepted and published in the CJHP heavily relies on the input provided by our highly valued network of expert reviewers. We will be reaching out to existing reviewers to verify their continued interest, accurate contact information, and areas of expertise. We also encourage CJHP contributors and readers to volunteer as new reviewers and/or to suggest others. This will be a key step in maintaining and improving the quality of our Journal.

Change is not easy, but it is often required to flourish in a shifting landscape. Full implementation of these changes will take time and will require all of us to adjust our usual approach to submitting manuscripts as well as our expectations around the publishing process. There will likely be a lag as we process the healthy number of manuscripts already submitted and/or approved for publication. Our small publications team and volunteer Editorial Board have much work to do to accommodate these changes. Although 
we will try to maintain similar turnaround times, some patience may be required on the part of those who submit manuscripts over the next few months. However, after everyone has adjusted to this new approach, we are confident that the result will be a higher-quality, more resilient version of the Canadian Journal of Hospital Pharmacy. We sincerely appreciate your support as we work through these processes, and we value your feedback along the way.

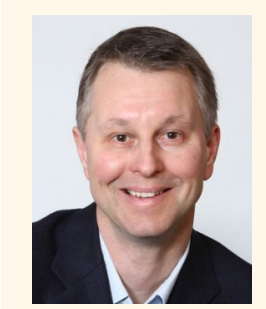

Stephen Shalansky, BSc(Pharm), PharmD, ACPR FCSHP, is the Clinical Coordinator of the Pharmacy Department, Providence Health Care, and is a Clinica Professor in the Faculty of Pharmaceutical Sciences, The University of British Columbia, Vancouver, British Columbia. He is also the Editor of the Canadian Journal of Hospital Pharmacy.

Competing interests: None declared.

Address correspondence to:

Dr Stephen Shalansky

Pharmacy Department

Providence Health Care

1081 Burrard Street

Vancouver BC V6Z 1 Y 6

e-mail: sshalansky@providencehealth.bc.ca

\section{ON THE FRONT COVER}

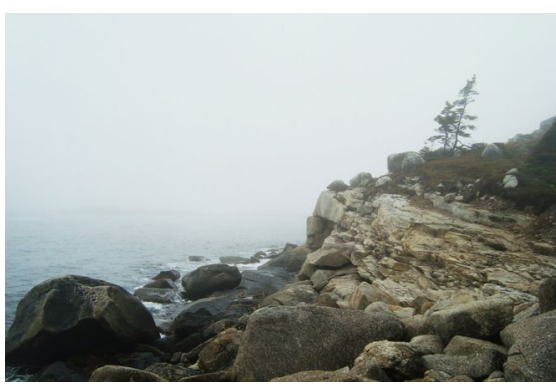

\section{Peggy's Cove, Nova Scotia}

The cover photo was taken by Heather Foley when she was a student at the University of Waterloo, while attending the 2009 Canadian Pharmacists Association conference, where she was honoured as the recipient of the Centennial Leadership Award. Heather is now an Adjunct Clinical Assistant Professor in the University of Waterloo's School of Pharmacy. She is also the Regional Clinical Coordinator for the Windsor Area and works as a full-time pharmacist consulting for a nonprofit organization that provides patient care services.

The CJHP would be pleased to consider photographs featuring Canadian scenery taken by CSHP members for use on the front cover of the Journal. If you would like to submit a photograph, please send an electronic copy (minimum resolution $300 \mathrm{dpi}$ ) to publications@cshp.ca. 